\title{
Celular e sala de aula: dos limites às possibilidades
}

\author{
Eliane Dias Gomes Alves ${ }^{1}$, Márcia de Freitas Vieira ${ }^{2}$ \\ ${ }^{1}$ Universidade Federal de Ouro Preto (UFOP) \\ CEAD - Campus Universitário Morro do Cruzeiro - Ouro Preto - MG \\ ${ }^{2}$ Universidade Federal de Ouro Preto (UFOP) \\ CEAD - Campus Universitário Morro do Cruzeiro - Ouro Preto - MG \\ \{elianedgalves@gmail.com, marcia.ipatinga@gmail.com\}
}

\begin{abstract}
Considering that the phone has interfered in the teaching and learning process and that its use can be optimized by teachers and students in favor of a contemporary education, this article aims to promote a reflection on the numerous possibilities of the device as a tool in building knowledge in order to mitigate the disruptive problems caused by their indiscriminate use in the classroom. It presents the results of an action research conducted in the State School John XXIII, in the city of Ipatinga - MG, with the students in the class of Information Technology, the 1st year of high school. The results of this analysis indicate that teaching with cell help is a real possibility waiting for exploitation by teachers, since mobile learning in a real context of the student, became the most motivating process, enabling the acquisition of new skills and knowledge.
\end{abstract}

Resumo. Considerando-se que o celular tem interferido no processo ensino e aprendizagem e que o seu uso pode ser otimizado por professores e alunos em prol de uma educação contemporânea, este artigo tem como objetivo promover uma reflexão sobre as inúmeras possibilidades do aparelho como instrumento na construção do conhecimento, de forma a amenizar os problemas de indisciplina causados pela sua utilização indiscriminada em sala de aula. Ele apresenta os resultados de uma pesquisa-ação realizada na Escola Estadual João XXIII, situada na cidade de Ipatinga - MG, com os alunos da turma de Tecnologia da Informação, do $1^{\circ}$ ano do Ensino Médio. Os resultados dessa análise apontam que ensinar com ajuda do celular é uma possibilidade real à espera de exploração por parte dos docentes, já que a aprendizagem móvel, num contexto real do aluno, tornou o processo mais motivador, possibilitando a aquisição de novas habilidades e conhecimentos. 


\section{Introdução}

O uso do celular nas salas de aula como uma ferramenta pedagógica, pode possibilitar o desenvolvimento intelectual e social dos alunos.

Os alunos de hoje se nos apresentam inequívoca e assustadoramente imersos na era da tecnologia, um ambiente permeado por informação e conhecimento. O telefone celular, que antes servia apenas para se comunicar, agora se transformou em um pequeno computador e é um instrumento onipresente em suas mãos.

Ainda que não esteja preparada para tal, ainda que não possua professores proficientes no uso da tecnologia, ainda assim, a escola, como espaço ideal de formação e informação, não pode deixar de explorar as potencialidades dos aparelhos móveis a favor do processo ensino-aprendizagem, inibindo sua utilização pelos alunos somente para entretenimento, o que causa distrações e indisciplina.

Partindo deste princípio, a equipe gestora da Escola Estadual "João XXIII" do município de Ipatinga/MG, desenvolveu um projeto de intervenção ${ }^{1}$ junto à comunidade escolar, em 2014, com o objetivo de aperfeiçoar o uso do celular pelo aluno no espaço escolar, inserindo-o com orientação e planejamento, no contexto ensino e aprendizagem. Nessa perspectiva, em discussão realizada com professores e pedagogos, percebeu-se que, ainda que timidamente e sem ser realmente contemplado, o uso do celular nas salas de aula está inserido nos tópicos "Desenvolvimento de Projetos", "Plano de Intervenção Pedagógica", "Novas Tecnologias e Educação" e "Disciplina e Formação Ética dos Alunos".

Dessa forma, foi realizada uma investigação com pais, professores, equipe pedagógica e alunos do Ensino Médio da referida escola, através de reuniões e questionários, com o objetivo de se fazer levantamentos sobre a importância do celular na vida dos alunos, de maneira a contribuir com o processo de ensino e aprendizagem. A partir daí, foi planejada uma atividade com o uso do celular, no Parque Ipanema ${ }^{2}$, usando o aplicativo whatsApp. Os alunos puderam comparar a velocidade com que as informações chegam até eles quando se usa ou não o celular. E, finalmente, apresentaram uma peça teatral para a comunidade escolar, com intuito de complementar a pesquisa e buscar novas rotas de aprendizagem.

As atividades planejadas e realizadas neste estudo buscaram apresentar a necessidade e a urgência de a escola incorporar a tecnologia móvel, em especial o celular, à sua prática, como uma experiência transformadora para os processos de ensino e aprendizagem.

A análise desta intervenção foi apoiada nas orientações das Diretrizes Curriculares Nacionais, que preveem a necessidade de utilização das diferentes mídias nos ambientes de aprendizagem e construção de novos saberes; nos conceitos de Ramos (2012) e Paiva (2012), que enfatizam a busca de novas estratégias para aprendizagem através das tecnologias disponíveis em sala de aula; nos conceitos de Carvalho (2000), que exploram a urgência de uma rediscussão sobre a relação tecnologia e a formação de

\footnotetext{
${ }^{1}$ Atividade proposta aos cursistas da $2^{\text {a }}$ turma do curso de Especialização em Gestão Escolar do Polo de Ipatinga/MG, ofertado pela Universidade Federal de Ouro Preto no âmbito do Programa Nacional Escola de Gestores da Educação Básica, na modalidade da Educação a distância.

${ }^{2}$ Parque Ipanema é um parque localizado no município de Ipatinga/MG, com mais de 1 milhão de metros quadrados, considerado uma das maiores áreas verdes do país situada dentro de um perímetro urbano.
} 
professores; teorias de Lucena (2006), que mostram que o papel da escola é formar seus alunos para serem cidadãos críticos; ainda, Lévy (1993), que aponta a necessidade de um letramento digital; teorias de Gomes \& Costa (2014), que defendem o uso do celular na promoção do desenvolvimento intelectual, cognitivo e social do aluno; e, por fim, Oliveira (1981), que diz que a tecnologia pode ser utilizada em sala de aula desde que seriamente pensada.

Buscando-se as possibilidades urgentes da utilização do celular em favor dos processos ensino e aprendizagem e da diminuição dos problemas de indisciplina causados pelo uso inadequado do celular em sala de aula, este trabalho apresenta possibilidades sobre o uso do celular como recurso pedagógico para as aulas no Ensino Médio, já que o acesso a conteúdos multimídia deixou de estar limitado a um computador pessoal e estendeu-se também às tecnologias móveis, proporcionando um novo paradigma educacional, o mobile learning ou aprendizagem móvel, através de dispositivos móveis.

\section{2. $O$ celular e a aprendizagem}

O processo educacional é permeado de estratégias que compõem as formas do ensinar e aprender. Nessa perspectiva, o professor pode se aliar às tecnologias, organizar e planejar adequadamente suas aulas, usando o celular como uma ferramenta pedagógica a favor da aprendizagem.

Com o desenvolvimento da ciência a escola amplia suas funções, passando a ser cobrada pela formação dos alunos em questões bem mais amplas que incluam também conhecimentos tecnológicos, já que atende a uma geração imersa na tecnologia. Deve ser capaz de oportunizar-lhe a construção de atitudes, habilidades e valores necessários que lhe permitam usar essa tecnologia produtiva e eficientemente no ambiente escolar, de forma a promover sua aprendizagem e não apenas como entretenimento e/ou motivo de conflitos entre professor e aluno, aluno e aluno, gerando graves faltas disciplinares.

Uma das maiores dificuldades enfrentadas pelo docente é lidar com o novo e buscar um novo olhar sobre o trabalho que é desenvolvido em sala, usando as novas tecnologias, inclusive o celular, torna-se um grande desafio. Porém, impedir o aluno de utilizar esses novos dispositivos eletrônicos durante as aulas é "andar na contramão" neste século.

De acordo com Lucena (2006), a escola deve formar seus alunos para serem cidadãos críticos, com o potencial para, idealmente, aperfeiçoar a sociedade a que pertencem. Nessa perspectiva, surgem as discussões sobre a necessidade de a escola se reinventar no que tange ás novas tecnologias, que precisam fazer parte do cotidiano dos alunos e serem encaradas como uma forma mais prazerosa e divertida dos "atos de ensinar e aprender".

Segundo Lévy (1993), além de se apresentar por meio das linguagens oral e escrita, o conhecimento atualmente se mostra também, e de maneira bastante significativa, ainda que as outras duas não possam ser descartadas, na forma digital. Um conhecimento que vem obrigando a escola a uma nova prática para elaborar seu fazer pedagógico contemplando cada vez mais novas metodologias que deem conta de alcançar a excelência tão almejada para a educação.

Recentemente, a Organização das Nações Unidas para a Educação, Ciência e Cultura (UNESCO), durante a Mobile Learning Week - conferência anual sobre aprendizagem móvel - publicou um guia trazendo 10 recomendações aos governos que 
desejam inserir o uso dos celulares em suas escolas e também 13 motivos para se fazer de tais aparelhos aliados da educação.

\begin{abstract}
Acredita-se que a utilização do celular promove o desenvolvimento intelectual, social e cognitivo da maneira conjunta, pois ele é um caminho, um estímulo para auxiliar na assimilação e acomodação dos conteúdos pedagógicos. Quando são propostos novos caminhos para aprender, o desenvolvimento intelectual acontece de forma natural, pois há o exercício da capacidade de pensar. (GOMES \& COSTA, 2014, p. 58)
\end{abstract}

Também Ramos (2012) defende que o uso das tecnologias móveis em sala de aula pode viabilizar a aprendizagem de forma diferenciada, proporcionando ao aluno aulas mais dinâmicas e atrativas, que o ajudem a aprender e apreender melhor os conteúdos e refletir sobre os problemas apresentados. Esta prática demanda um novo formato de educação, o desenvolvimento de um conjunto de atividades didáticopedagógicas a partir das tecnologias disponíveis na sala de aula e as que os alunos trazem consigo.

A utilização orientada pelos professores de forma adequada pode auxiliar na educação, melhorando a compreensão dos conteúdos aplicados durante as aulas, podendo, inclusive, ajudar no desenvolvimento dos alunos quanto à capacidade de reflexão crítica e soluções de problemas discutidos em sala de aula.

A sociedade está cada vez mais tecnológica e a escola mais do que nunca precisa se adequar, pois giz, quadro e livros não são mais atrativos suficientes para uma demanda jovem, cada vez mais "antenada", imersa no mundo virtual. Não adianta proibir o uso do celular, principalmente em sala de aula, é preciso buscar mecanismos que aproveitem seus recursos em favor da educação. Uma educação "conectada" poderá apresentar menores índices de evasão, menos casos de indisciplina e maior aproveitamento, visto que a aprendizagem poderá se tornar mais atraente tanto para quem ensina como para quem aprende. Nesta perspectiva, as tecnologias podem tornarse elementos integradores dos ambientes de aprendizagem desde que sejam pensadas, discutidas e planejadas com base nos reais contextos educacionais com seus limites e possibilidades (OLIVEIRA, 1981, p. 2).

Os atuais meios de comunicação - internet, revistas, televisão - têm atualmente grande poder pedagógico, visto que aliam uma gama de recursos que oportunizam aos alunos agilidade e interatividade. A educação e a comunicação estão interligadas, e por que não se apropriar da tecnologia para transformar a informação em conhecimento?

Valorizar a utilização dos recursos tecnológicos nas salas de aula, de
forma a favorecer o aprendizado dos alunos e tornar o processo
de ensino e aprendizagem mais significativo para as crianças e
adolescentes, faz com que o aluno utilize ferramentas que já fazem
parte do seu dia a dia (PAIVA, 2012, p. 1).

É necessário que professor e aluno conheçam maneiras eficientes de utilização, principalmente no que diz respeito ao telefone celular como instrumento não só de comunicação, mas também com grandes possibilidades na construção do conhecimento. Para isso, o Projeto Político Pedagógico das escolas precisam conter propostas de trabalho que permitam e contemplem seu uso:

Concretamente, o projeto político-pedagógico das unidades escolares que ofertam o Ensino Médio deve considerar: VIII - utilização de diferentes mídias como processo de dinamização dos ambientes de aprendizagem e construção de novos saberes (Diretrizes Curriculares Nacionais para o Ensino Médio, 2011, Cap. VIII). 


\section{Metodologia}

A intervenção desenvolvida na escola pesquisada teve como base fundamental a construção de estratégias para favorecer o aproveitamento das tecnologias móveis, em especial o celular, nas salas de aula, no processo de ensino e aprendizagem, estabelecendo, para tal, uma concepção específica de pesquisa inserida na ação. De acordo com Thiollent (1997), a pesquisa-ação tem como objetivo proporcionar novas informações, gerar e produzir conhecimento que traga melhorias e solução para toda organização.

A metodologia partiu inicialmente de uma investigação embasada na reflexão do grupo composto por 13 professores, 04 pedagogos, 22 pais e 39 alunos da $1^{\text {a }}$ série do Ensino Médio, da turma de Tecnologia da Informação sobre a utilização indiscriminada do celular na escola durante as aulas e a necessidade de se planejar e orientar os alunos, quanto ao uso do celular como instrumento a favor da aprendizagem. Neste intuito, a coleta de dados foi realizada por meio de encontros, discussões e aplicação de questionários formados por onze questões, sendo nove fechadas e duas abertas, a alunos, professores, pedagogos e pais.

O tema proposto foi inserido no planejamento da disciplina de Tecnologia da Informação e discutido durante as aulas entre os alunos da turma, tendo o professor da disciplina como orientador em roda de conversa na própria sala.

Após o levantamento e análise dos resultados, foi feita uma sensibilização da comunidade escolar, direção, equipe pedagógica, professores, alunos e pais, sobre o rumo que a tecnologia vem tomando nos relacionamentos interpessoais. Foi exibido o vídeo de sensibilização "Off ou on-line: de que lado você está?" a pais, alunos e professores, e, posteriormente, discutidas as abordagens apresentadas no vídeo para que fossem alertados sobre o quanto a tecnologia está cada dia mais inserida na vida das pessoas, transformando relações, hábitos e atitudes.

$\mathrm{Na}$ expectativa de se colocar em prática o uso do celular em função da aprendizagem, foi realizada uma pesquisa de campo com todos os alunos da turma. A pesquisa consistiu em uma visita ao Parque Ipanema e realização da seguinte atividade: a turma foi dividida em dois grupos; um deles deveria fazer um levantamento da parte natural e arquitetônica do parque, usando o celular, e compartilhar esse levantamento com os demais componentes daquele grupo utilizando o aplicativo whatsApp. O grupo se subdividiu em outros dois grupos, intitulados "Natural" e "Arquitetura", e repassaram fotos de toda a estrutura do parque pelo celular de forma imediata. Na sequência, os dois subgrupos se reuniram para discussões sobre as informações levantadas. Interessante destacar a habilidade com a qual os alunos manusearam o celular e todos os seus aplicativos, o que naturalmente poderia ser aproveitado em uma aula, na sala, devidamente planejada e orientada pelo professor.

O segundo grupo percorreu os mesmos caminhos do primeiro, porém não usou a Internet, nem o aplicativo whatsApp. Os alunos chegaram a tirar fotos, mas não tiveram a oportunidade de compartilhar e discutir com os demais componentes do grupo e só o fizeram no momento em que se encontraram na escola.

A partir desse trabalho no parque, os alunos apresentaram à comunidade uma peça teatral, escrita por um dos participantes do projeto, refletindo sobre os pontos positivos e negativos da tecnologia e do uso do celular a favor da aprendizagem. Com essa intervenção, procurou-se transformar a escola, em especial a sala de aula, em um lugar privilegiado, onde o aluno pudesse acessar e discutir conhecimentos ao mesmo tempo em que constrói seus próprios saberes. 


\section{Apresentação e discussão dos resultados}

Os resultados demonstrados na figura 1 indicam que dos 13 professores pesquisados mais de $60 \%$ concordam com o aproveitamento do celular nas aulas com atividades dinâmicas e orientadas por eles, de acordo com o seu planejamento. Nenhum professor concorda com o acesso livre às tecnologias, em particular o celular, durante suas aulas.

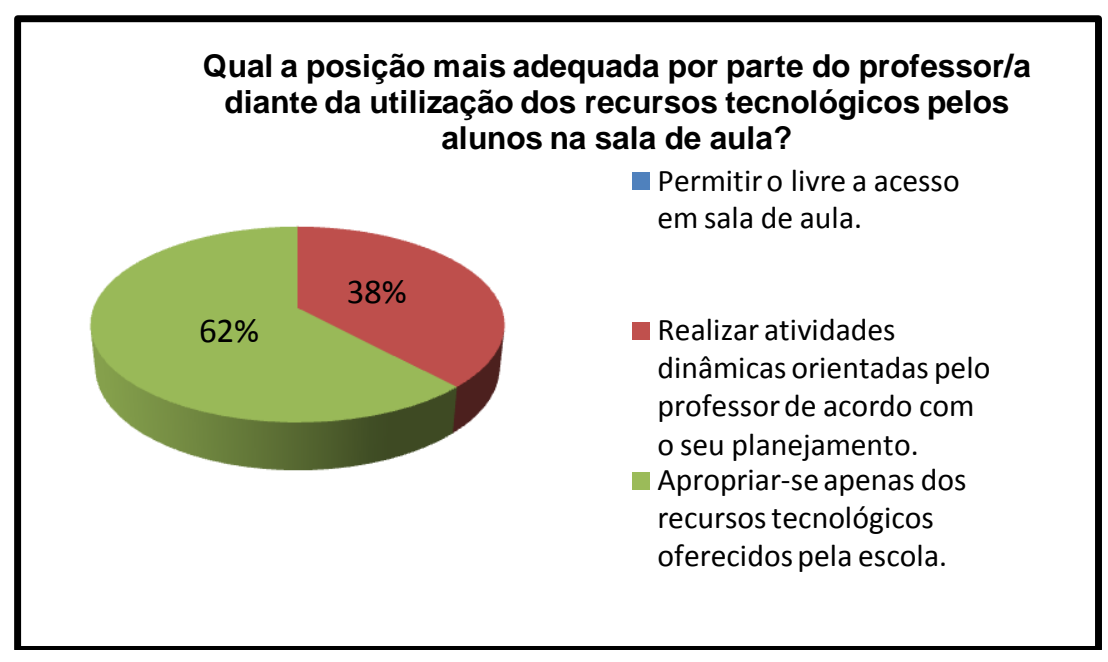

Figura 1. Postura do professor diante da utilização do telefone celular pelo aluno em classe Fonte: Autoria própria

Quanto aos alunos, dos 39 alunos participantes da pesquisa, 33 têm celular e concordam em gênero e grau com a adaptação do celular adequadamente às aulas, propiciando uma discussão de diversos temas relacionados com as matérias ministradas pelos professores. Eles reconhecem que o uso da tecnologia de forma desordenada não vai ajudá-los em nada, porque eles precisam ampliar o universo da leitura e do conhecimento. Assim, ao serem questionados sobre se usam alguma tecnologia em sala de aula, $80 \%$ dos alunos disseram que sim e $20 \%$ que não. E ainda, quanto ao uso da tecnologia distrair a sua atenção, 67,5\% disseram que sim e 32,5\% disseram que não.

Embora $77,5 \%$ dos alunos pesquisados tenham dito que usaram o celular apenas como forma de entretenimento em classe e $22,5 \%$ não usaram o celular de maneira inadequada durante as aulas, percebeu-se que os alunos apoiaram o uso do celular de forma orientada nas aulas para complementação dos conteúdos ministrados pelos professores.

Com relação à pesquisa feita com 22 pais sobre as consequências do uso inadequado de tecnologias nas salas de aula, 15\% deles responderam que traz conflitos entre alunos, $25 \%$ conflito entre alunos e professores e $60 \%$ disseram que afeta a aprendizagem dos alunos, conforme demonstrado na figura 2 . Revelaram ainda, que dão um celular aos filhos por questão de segurança, mesmo sabendo que o seu uso pode afetar a concentração de seus filhos nos estudos, quando utilizado de forma incorreta. 


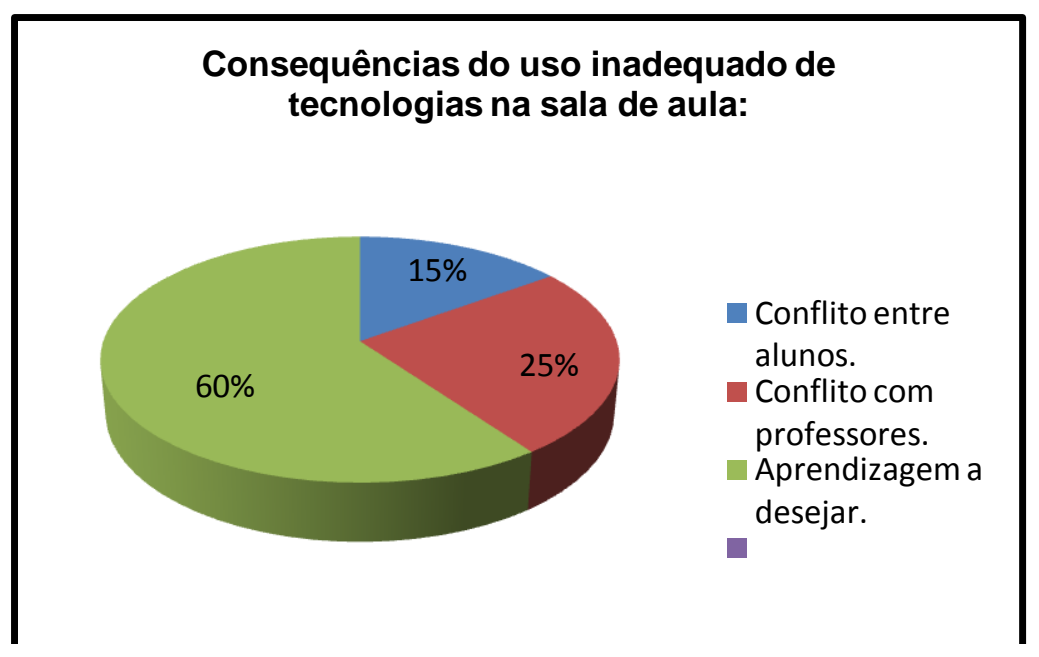

Figura 2. Conseqüências do uso inadequado da tecnologia em sala de aula

Fonte: Autoria própria.

Em tempos em que crianças e jovens estão cada vez mais plugados às redes sociais, afetando claramente as relações familiares, considera-se importante descobrir como os pais administram o uso do celular pelos filhos em suas próprias casas. Segundo os pais, $15 \%$ não se preocupam com o assunto já que os filhos não possuem telefone móvel. Daqueles cujos filhos possuem celular, 22,5\% determinam os horários de uso, $22,5 \%$ dão total liberdade para os filhos na questão celular e $40 \%$ não se incomodam, pois os filhos têm celular, mas sem acesso à internet.

Nas respostas ao questionário, as pedagogas disseram que o uso inadequado do celular durante as aulas traz conflitos entre colegas, com os professores e implica seriamente a aprendizagem, atrapalhando a concentração do aluno e dificultando sua socialização. Segundo elas, os alunos trazem o aparelho para a escola para usar as redes sociais, dar segurança para as famílias e, ainda, ouvir música, tirar fotos e filmar. Afirmaram que nenhum professor permite o livre acesso ao dispositivo móvel em suas aulas, uma pequena parcela orienta seu uso, mas que a maioria ainda não se apropriou das possibilidades dos recursos tecnológicos que os alunos carregam consigo.

Estes dados permitem seguramente dizer que os celulares estão aí, hoje transformados em microcomputadores portáteis, nas mãos dos alunos, e que devem e precisam urgentemente ser aproveitados, de maneira sistemática e estruturada, em potencialidades pedagógicas.

\subsubsection{Discussão}

Segundo Moura (2009), as tecnologias estão nas mãos dos alunos e, para eles, o futuro é móvel e expressar-se por meio do celular hoje é regra. Eles possuem competências comunicativas especiais que precisam e podem, através de estratégias inovadoras, serem transformadas em ações educativas se pretendemos prepará-los para as demandas do século XXI.

Durante os levantamentos feitos, ficou claro que o uso indevido do celular na sala de aula não traz conflitos entre os alunos, mas sim torna difícil a relação professor/aluno. É de se esperar que o professor, como educador, deixe de ser 
conservador e perca a insegurança ao lidar com os novos suportes tecnológicos e se atualizem, procurando interagir com o aluno, tornando-se parceiros nesse trabalho.

Considerando-se as ações e reflexões apresentadas, observou-se o quão a tecnologia está cada dia mais inserida na vida das pessoas, transformando relações, hábitos e atitudes. Compreendeu-se e concluiu-se que ela é algo bom, com diversas possibilidades, mas que não pode inviabilizar momentos importantes e felizes com família e amigos e não pode jamais comprometer os processos de ensinar e aprender.

O que se percebe na pesquisa é que tanto professores quanto alunos sabem que podem se apropriar da tecnologia, em especial o celular, durante as aulas, mas os docentes têm receio, talvez porque seja necessário desenvolver um planejamento para uma aula desta forma.

Outro fator importante, é que muitos professores têm receio de que, se autorizarem o uso do celular nas salas de aula, o aluno interprete isso como autorização para usá-lo quanto e quando quiser. Para evitar isso, é importante regularizar o uso do aparelho em sala de aula pela escola, com regras bem definidas, verificando se isso está desrespeitando ou não uma lei.

Importante destacar aqui, que esta proposta inovadora de trabalho, rompendo com o conservadorismo, mesmo que timidamente, já rende frutos para a práxis da Escola Estadual "João XXIII". Como relata Paiva (2012), valorizando os recursos tecnológicos que já fazem parte do dia a dia do aluno de maneira a favorecer o aprendizado por meio de um processo mais significativo, é que alguns professores, perdendo o receio, já começaram a se apropriar da ideia do uso do celular para ensinar.

Para exemplificar, a professora de Inglês preparou uma aula para pesquisar o assunto "Haloween" em sala, usando o celular. Dividiu a turma em grupos e, no momento curto da aula, eles pesquisaram sobre o assunto e até fizeram um "print" de imagens alusivas ao "Haloween". Em cada grupo formado por cinco alunos, quatro tinham celular. Também, a professora de Arte permitiu aos seus alunos o desenvolvimento em sala de aula de uma pesquisa na internet sobre a releitura da obra Abaporu, de Tarsila do Amaral, formando os grupos e autorizando que eles pesquisassem, registrassem no caderno, fizessem o "print" de uma imagem e compartilhassem a imagem e o significado de releitura de uma obra pelo whatsApp.

É interessante ressaltar que os alunos levantaram questões sobre os assuntos e dividiram com os colegas na sala de aula a pesquisa, desenvolvendo os trabalhos em grupo, em um tempo menor, de forma mais atraente e com resultados mais positivos, porque o alcance do objetivo da aula foi maior.

Nesses caminhos, pôde-se, enfim, constatar que a educação cada vez mais exige de todos nós uma inovação e renovação permanentes que nos oportunizem, segundo Carvalho (2000), uma rediscussão sobre as relações tecnologia e escola em busca de novas formas de incrementar os processos de ensino e aprendizagem, ampliando possibilidades e promovendo as mudanças necessárias a uma instituição educacional contemporânea, conectada aos novos tempos.

\section{Considerações finais}

Ao longo do caminho percorrido, procurou-se investigar quais os limites e as possibilidades para o uso do celular na sala de aula, como um instrumento a ser utilizado em favor do processo de aprendizagem. Partiu-se das premissas apresentadas pelos estudiosos da educação de que a tecnologia móvel, em especial o celular, deve fazer parte do contexto da sala de aula, visto que a escola prepara o aluno para a 
sociedade em que está inserido e, hoje, o mundo que se nos apresenta é totalmente virtual, sendo pertinente uma rediscussão sobre tecnologia e formação de professores, em busca de oportunidades para uma otimização do uso de tal aparelho na aquisição de novas habilidades, novos saberes.

Sabe-se que o celular é uma tecnologia que sai de graça para a escola, um minicomputador pago pelos pais, e excluí-lo hoje do processo ensino e aprendizagem é dar as costas às potencialidades e aos benefícios que esse instrumento oferece num mundo digital que se nos apresenta de forma inexorável. Em todo o processo ficou bastante claro, que alguns professores ainda não conseguem associar o avanço tecnológico e o uso do celular a uma aprendizagem eficaz. Talvez por comodismo ou por não querer descobrir o novo e possível.

Pelo caminho percorrido até aqui, mesmo que o uso do telefone celular seja proibido por lei e pela escola, ele pode e deve se tornar um recurso pedagógico de grande importância no contexto escolar. Percebe-se que ele representa uma tecnologia que pode ser aplicada positivamente dentro das salas de aula, no desenvolvimento dos conteúdos, contribuindo para a aprendizagem do aluno, se sua utilização for orientada nesse sentido.

Há uma infinidade de possibilidades de uso pedagógico dos telefones celulares modernos em sala de aula e fora dela. Isso certamente depende da forma como o professor usa a tecnologia para si mesmo, em suas aulas e com os seus alunos. Quem não vê nenhum uso pedagógico para o rádio, a televisão, a máquina fotográfica, a filmadora, o gravador, a calculadora, a agenda, etc., então, também não verá nenhuma utilidade para o celular, pois é isso que ele representa hoje em dia: não é mais um simples telefone, o celular é uma central de multimídia computadorizada.

Assim, mesmo entendendo que se fazem pertinentes mais estudos feitos por professores e alunos em busca de uma nova organização das atividades escolares, o uso do celular nas salas de aula, devidamente orientado pelo professor, pode criar várias outras possibilidades como recurso pedagógico para as aulas no Ensino Médio, tais como: a melhora da educação ao que se refere a implementação de projetos que viabilizem a chegada de informações em tempo hábil, sobre questões ambientais, políticas e sociais e ainda melhorar a comunicação e o aprendizado, otimizando o tempo na sala de aula, num ambiente de aprendizagem capaz de promover as competências necessárias às solicitações deste nosso século.

\section{Referências}

BRASIL (1996). “Lei de Diretrizes e Bases da Educação Nacional”.

BRASIL (2011). "Diretrizes Curriculares Nacionais para o Ensino Médio 4/5/2011. Projetos Políticos Pedagógicos". Equipe Técnica do DPEM/ NETO, Alípio dos Santos; LAZZARI, Maria de Lourdes; QUEIROZ, Maria Eveline Pinheiro Villar de; AMARAL, Marlúcia Delfino; ARAÚJO, Mirna França da Silva de; NETO, Pedro Tomaz de Oliveira.

CARVALHO, Marília G.; BASTOS, João A. de S. L., KRUGER, Eduardo L. de A. (2000). "Apropriação do conhecimento tecnológico". CEEFET-PR, Cap. Primeiro.

ESCOLA ESTADUAL JOÃO XXIII (2014). "Projeto Político Pedagógico da E. E. João XXIII". Ipatinga: EEJXXIII. 
GOMES, Martha Luciene Rocha; COSTA, Mônica Suely Martins (2014). "Conectados ao celular". AMAE Educando / MAGISTRA - Edição 3.

LÉVY, Pierre (1993). "As tecnologias da inteligência. O futuro do pensamento na era da informática". Rio de Janeiro: Editora 34.

LUCENA, Marisa (2006). "Integração das tecnologias na gestão escolar”. In: Liderança, gestão e tecnologias: para a melhoria da educação no Brasil / coords. Fernando Jose de Almeida. Maria Elizabeth B. B. de Almeida. - São Paulo. 168 p .

MORAN, José Manuel (1998). "Mudanças na comunicação pessoal”. São Paulo: Paulinas.

MOURA, Adelina. "Geração Móvel: um ambiente de aprendizagem suportado por tecnologias móveis para a Geração Polegar”. Disponível em: $<$ http://adelinamouravitae.com.sapo.pt/gpolegar.pdf $>$. Acesso em: 23 de setembro de 2014.

OLIVEIRA, Alice Virginia Brito de (1981). "O uso das mídias na sala de aula: resistências e aprendizagens". PPGE/UFAL. Disponível em: http://www. webfactional.com. Acesso em 24 de maio de 2014.

PAIVA, Ana Paula Barros de (2012). "Celular dentro da escola? Sim!” Disponível em www.planetaeducacao.com.br/portal/artigo.asp?artigo=2229. Acesso em 22 de setembro de 2014.

PEDROSA, Deivison (2012). "Motivacional - on ou off - de que lado você está?". Disponível em www.youtube.com. Acesso em 07/06/2014.

RAMOS, Márcio Roberto Vieira (2012). "O uso de tecnologias em sala de aula". V Seminário de Estágio do Curso de Ciências Sociais do Departamento de Ciências Sociais - UEL. Londrina. 11/2012.

THIOLLENT, Michel (1997). "Pesquisa-Ação nas Organizações”. São Paulo, Atlas. Disponível em HTTP://dx.doi.org/10.15603/1982-8756/roc.v4n7p84-87. Acesso em 09 de abril de 2015.

UNESCO (2013). "Dez dicas e treze motivos para usar o celular na sala de aula". Disponível em porvir.org/porfazer/10-dicas-13-motivos-para-usar-celular. Acesso em 23 de janeiro de 2015.

YIN, R. K (2005). "Estudo de caso: planejamento e métodos", $3^{\mathrm{a}}$ ed., Porto Alegre: Bookman. Disponível em https://saudeglobaldotorg1.files.wordpress.com. Acesso 09 de abril de 2015. 